\title{
Erratum to: Sex- and age-dependent DNA methylation at the 17q12-q21 locus associated with childhood asthma
}

Anna K. Naumova • Abeer Al Tuwaijri · Andréanne Morin · Vanessa T. Vaillancourt • Anne-Marie Madore · Soizik Berlivet • Hamid-Reza Kohan-Ghadr •

Sanny Moussette $\cdot$ Catherine Laprise

Published online: 14 April 2013

(c) Springer-Verlag Berlin Heidelberg 2013

\section{Erratum to: Hum Genet}

DOI 10.1007/s00439-013-1298-z

Unfortunately, one of the author names was incorrectly spelled out in the published article. The correct spelling should read as Vanessa T. Vaillancourt.

The online version of the original article can be found under doi:10.1007/s00439-013-1298-z.

A. K. Naumova $\cdot$ S. Berlivet Department of Obstetrics and Gynecology,

McGill University, Montreal, QC H3A 1A1, Canada

A. K. Naumova · A. Al Tuwaijri

Department of Human Genetics, McGill University,

Montreal, QC H3A 1B1, Canada

A. K. Naumova $(\bowtie) \cdot$ H.-R. Kohan-Ghadr · S. Moussette The Research Institute of the McGill University Health Care Centre, Montreal, QC H3H 2R9, Canada

e-mail: anna.naoumova@mcgill.ca

A. Morin · V. T. Vaillancourt · A.-M. Madore - C. Laprise Département des Sciences Fondamentales, Université du Québec

à Chicoutimi, Chicoutimi, QC G7H 2B1, Canada 